\title{
A impressão 3D contribuindo em projetos de design da informação
} The 3D printing contributing in information design projects

\author{
Natal Chicca Junior, Leonardo Gómez Castillo, Solange Galvão Coutinho
}

usuário, inclusão, impressão 3D

O artigo apresenta conceitos e definições sobre o design da informação para compreender melhor a atuação do designer e os objetivos focando no projeto de suas criações e as relações com os usuários. $E$ se, por um lado, algumas metodologias buscam o design centrado ao usuário, por outro, alguns designers ainda excluem o usuário no desenvolvimento do projeto. Enquanto não surge uma solução ou ponto de equilíbrio, ferramentas, como a tecnologia assistiva, ganham destaque ao permitir autonomia e independência a usuários deficientes ou com limitações em um mundo que não é acessível a todos. E, por fim, são apresentados estudos desenvolvidos utilizando a tecnologia de impressão 3D na produção de objetos de aprendizagem táteis responsáveis pela inclusão do acesso à informação por usuários com deficiência visual. Os estudos de casos também são utilizados para contestar e ampliar alguns conceitos sobre design da informação.

user, inclusion, 3D Printing

This paper presents concepts and definitions about information design to better comprehend the role of the designer and the objectives focusing on the design of their creations and the relationships with its users. And considering some design methodologies seek to user centered design, while others still exclude the user during the development of the project. Until there's not a definitive solution or equilibrium point, some tools, such as assistive technology, stands out by allowing autonomy and independence to disabled or movement limited users in a world that is not accessible to everyone. Finally, there are some developed studies using 3D printing technology to produce learning tactile objects responsible for the inclusion of visually impaired users. The case studies are also used to challenge and expand some concepts about information design.

\section{Introdução}

A Sociedade Brasileira de Design da Informação (SBDI, 2001) define o design da informação como uma área do design gráfico que objetiva equacionar os aspectos sintáticos, semânticos e pragmáticos que envolvem os sistemas de informação através da contextualização, planejamento, produção e interface gráfica da informação, junto ao seu público alvo. Seu princípio básico é o de otimizar o processo de aquisição da informação, efetivado nos sistemas de comunicação analógicos e digitais. O design da informação está, de acordo com esta definição, diretamente associado ao design gráfico e busca transmitir da maneira mais eficiente possível uma determinada informação a seu usuário. 
De modo mais amplo, a International Institute for Information Design (IIID, 2007) considera o design da informação como a definição, planejamento e formatação do conteúdo de uma mensagem onde existe a intenção de satisfazer as necessidades informacionais em relação às necessidades dos usuários. Apesar de parecer incompleto, não enfatizar o vínculo com um determinado segmento do design pode demonstrar um caráter mais amplo de atuação pois mesmo que o design da informação contemporâneo esteja mais relacionado à parte gráfica (impressa ou digital), ele pode também transmitir conteúdo além do visual e estimular outros sentidos.

O aspecto do design da informação não se limitar ao aspecto visual é reforçado no próprio documento, desenvolvido pelo grupo IDX da IIID (2007), que contém sugestões do conjunto de competências em design da informação. Na parte referente ao ato de projetar informações é indicado aos designers utilizarem também informação verbal, pictórica, acústica, tátil e/ou olfativas, que molda e estrutura de acordo com os princípios da psicologia perceptiva e cognitiva. Da mesma forma, este artigo tem como objetivo demonstrar como a impressora 3d pode vir auxiliar o design da informação ao criar elementos informacionais que explorem, além da visão, outros canais sensoriais, estimulando a percepção e cognição na construção do conhecimento. Além de explorar diferentes meios para transmitir conteúdos educacionais, a tecnologia de impressão $3 d$ também busca tornar o acesso à informação mais acessível.

Buscando ainda outras definições, Horn (1999) enfatiza que o design da informação é entendido como a arte e a ciência de preparar as informações para que elas possam ser usadas por pessoas com eficiência e eficácia. Retomando novamente às definições da IIID (2007), a informação pode ser categorizada como o resultado do processo, da manipulação e organização de dados de maneira que adicione conhecimento para a pessoa a qual o está recebendo. $E$ infodesign é a definição, planejamento e modelagem do conteúdo de uma mensagem e os ambientes em que é apresentada, com o intuito de satisfazer as necessidades de informações dos destinatários. Em ambos os casos é importante notar a preocupação no preparo das informações para uma melhor compreensão por parte do usuário. Shedroff (1999) também considera o design da informação responsável pela transformação de dados em informação válida e significativa que precisa estar atenta ao conhecimento das necessidades do usuário com um mínimo entendimento de suas atitudes.

Preocupados com o usuário, Wildbur \& Burke (1998) definem o design da informação como uma atividade relacionada à seleção, organização e apresentação da informação para uma determinada audiência. Ao especificar um determinado público, aparentemente não existe mais a necessidade em conseguir disseminar uma mesma informação a todos e sim, segmentar para um usuário específico para que ela seja compreendida da melhor forma possível (eficiente e eficaz ao retomar a definição de Horn). Entretanto, ao considerar uma mensagem voltada a um determinado público pode garantir uma compreensão melhor do que está sendo informado, pela possibilidade de ser mais específico o conteúdo e na forma a qual a mensagem será transmitida, mas vai contrário aos princípios do design universal, que segundo Horton (2006), provê acesso livre e ilimitado a todas as pessoas, com ou sem deficiência, a todo conteúdo desenvolvido por meio do projeto inclusivo permitindo a todos o direito à informação.

\section{Tecnologia assistiva e o acesso à informação}

Algumas ferramentas foram especialmente desenvolvidas para simplificar as atividades do cotidiano tais como os talheres, canetas, computadores, controles remotos, veículos, dispositivos móveis, entre diversos outros objetos que já estão assimilados à vida das pessoas. Horton (2006) explica que, no design universal, cada um destes objetos é universalmente acessível apenas se perceptível a todos os indivíduos sem necessidade $\square$ de adaptação. $O$ autor define que não se trata de desenvolver outro conteúdo específico e direcionado para suprir uma deficiência, mas permitir ao indivíduo, com desabilidades, o acesso ao mesmo produto, ambiente e/ou informação. No entanto, diferente do que é sugerido pelo autor, enquanto existir produtos, 
ambientes e/ou informações não acessíveis, as tecnologias assistivas permitem as pessoas com deficiência a ter autonomia e independência.

Bersch (2013) classifica as tecnologias assistivas como instrumentos que facilitam o desempenho em funções pretendidas. Ou, de forma mais clara, Radabaugh (1993) resume que a tecnologia torna as coisas mais fáceis para as pessoas sem deficiência, enquanto àquelas com deficiência, a tecnologia torna as coisas possíveis. A tecnologia assistiva (TA), portanto, deve ser entendida como uma forma de auxílio as atividades diárias que promoverá a ampliação de uma habilidade funcional, além de possibilitar a realização da função desejada e que se encontra impedida por circunstância de deficiência ou algum outro impedimento. O maior objetivo da TA, segundo Bersch (2013), é poder proporcionar à pessoa com deficiência maior independência, qualidade de vida e inclusão social, através da ampliação de sua comunicação, mobilidade, controle de seu ambiente, habilidades de seu aprendizado e trabalho.

Segundo Gruenwald (2014), o acesso ao material didático impresso, como livros, apostilas, etc. é uma das maiores barreiras atuais na área da Educação para pessoas com deficiência visual. A autora aponta alternativas de tecnologia assistiva como, por exemplo, programas leitores de tela, dando aos alunos acesso ao conteúdo textual. No entanto, considera o acesso às imagens, presentes nos conteúdos digitalizados, um grande problema a ser resolvido. A solução utilizada é uma descrição textual para cada imagem presente no material didático. $O$ problema é que mesmo se existisse uma tecnologia capaz de descrever cada imagem automaticamente, ela não forneceria autonomia para as pessoas cegas criarem suas próprias interpretações sem o auxílio de intermediários. A justificativa é que a técnica pode até funcionar com imagens simples, mas para imagens complexas, fazer uma descrição apurada pode ser um grande problema, tanto por falta de espaço nos campos para associação de imagens quanto na possível inabilidade dos envolvidos para selecionar e descrever elementos importantes dessas figuras. E, por outro lado, cada vez é mais comum inserir imagens complexas em material didático, devido ao acesso mais fácil a imagens obtidas através de microscópios, telescópios ou satélites e que contêm inúmeros detalhes bem específicos. Uma das soluções encontradas é a produção de objetos de aprendizagem táteis feitos através de impressão 3D.

\section{Objetos de aprendizagem táteis para deficientes visuais}

Entre as diversas categorias existentes de tecnologia assistiva, a tecnologia háptica, de acordo com Hayward et al. (2004), é um recurso de acessibilidade bastante utilizado em diferentes áreas, entre elas: saúde, educação, entretenimento, indústria automotiva, telefonia móvel e robótica.

A acessibilidade de imagens através da tecnologia háptica, segundo o IMS - Instructional Management Systems $\square$ (2002), reduz o esforço mental através do feedback proveniente da combinação do áudio e tato e têm gerado resultados muito eficientes ao produzir representações gráficas acessíveis para usuários cegos. Adam \& Macedo (2013) descrevem que a associação de diferentes estímulos, combinados aos pares, geram efeitos aditivos na memória, de acordo com o enunciado da teoria do código duplo. O estudo de caso, a ser apresentado a seguir, trabalha com uma criativa aplicação de objetos de aprendizagem que estimulam os diferentes sentidos dos alunos.

Kolitsky (apud AAGAARD \& KOLITSKY, 2013) é professor universitário e ensina em cursos online voltados as ciências biológicas, desde 2001, e seus materiais do curso são fortemente baseados em imagens. Ao ponderar sobre os diferentes estilos de aprendizagem de suas aulas, ele entendeu que os alunos com deficiência visual não seriam capazes de experimentar e compreender os objetos de aprendizagem com base em imagens da mesma maneira que seus alunos com visão.

Motivado em criar diferentes formas de estímulos para os alunos com deficiência visual e, aproveitando o fato que já havia experimentado a impressão 3D durante vários anos, ele percebeu que poderia converter de forma rápida e fácil os arquivos 2D extraídos de microscópios

Anais [Pôster] do $7^{\circ}$ Congresso Internacional de Design da Informação | CIDI 2015

Proceedings [Poster] of the 7th Information Design International Conference / IDIC 2015 
e telescópios para objetos tridimensionais. Desta forma transformaria seus exemplos bidimensionais em objetos de aprendizagem tátil para os seus alunos. E Kolitsky aprimorando ainda mais, ao invés de meros objetos sólidos estáticos, incorporou 'elementos inteligentes' nos seus objetos de aprendizagem táteis. Um exemplo é a representação de imagens bidimensionais de uma célula em divisão, extraídas através de um microscópio, impressa através de objetos 3-D que representam as diferentes fases celulares. Junto com os objetos, ele também imprime legendas em braile com os nomes de cada fase celular. Em seguida, ele usa uma caneta inteligente para codificar um pequeno ponto de informação auditiva sobre cada objeto. $O$ resultado é um objeto de aprendizagem que pode ser experimentado através do toque e também do som.

Toscano (2014) descreve um outro projeto muito semelhante, desenvolvido na Universidade Federal do Espírito Santo (UFES), com a colaboração do Instituto Nacional de Tecnologia (INT). Eles reproduziram réplicas em escalas ampliadas de células em três dimensões com o objetivo de difundir o estudo científico entre estudantes cegos ou com baixa visão, de maneira que eles consigam, por meio do tato, conhecer o formato das células.

Os pesquisadores geram os modelos digitais, no Laboratório de Ultraestrutura Celular da UFES, a partir de imagens reais das células utilizando técnicas de microscopia eletrônica de transmissão. Essa tecnologia possibilita que a estrutura celular seja reproduzida de forma proporcional à verdadeira.

Após o desenvolvimento da estrutura digital, os modelos são enviados para a equipe de design de produtos do INT, onde são materializados por meio de uma impressora 3D. As réplicas produzidas passam a integrar o acervo permanente do Museu de Ciências da Vida da UFES.

Outras iniciativas, como o projeto Hands on Search ${ }^{1}$, parceria entre o site de buscas Yahoo! Japão junto com a agência criativa Hakuhodo Kettle Inc., que consiste em um projeto voltado para crianças portadoras de deficiência visual. Através de uma máquina que combina o sistema de buscas online por comando de voz junto com uma impressora 3D, as crianças podem pedir para a maquina o que elas gostariam de pesquisar na internet. Ao encontrar o termo pesquisado, a impressora 3D é ativada, transformando o resultado da busca em objetos sólidos que as crianças podem tocar e sentir. O equipamento do Hands on Search foi instalado na Escola de educação em necessidades especiais para os deficientes visuais, da Universidade de Tsukuba, no Japão.

\section{Considerações finais}

O artigo apresentou algumas definições de design da informação e após alguns agrupamentos foi possível perceber a dificuldade em chegar em um consenso. Inclusive, durante o processo de agrupamento, não foi raro notar o confronto de alguns argumentos chegando a se questionar se realmente é possível chegar a uma única definição. Contudo, mais importante do que definir o que vem a ser o design da informação, foi identificar um ponto em comum, nas variadas definições, que trata da modelagem do conteúdo de uma mensagem de forma a satisfazer as necessidades informacionais dos usuários de forma eficiente e eficaz.

Os conceitos de design da informação também podem ser combinados com os de design universal pois eles não são apenas responsáveis por tratar e planejar a melhor forma de transmitir a mensagem, mas também torná-la acessível a todas as pessoas. Analisando o design, de forma mais ampla, ele está inserido nas ciências sociais cujo objeto de estudo é a própria vida social, sendo as pessoas parte dela. O designer, portanto, está diretamente relacionado aos seus usuários e sua preocupação maior não deve ser desenvolver um produto ou ambiente, mas sim soluções; estas feitas para tornar a vida das pessoas melhor de alguma forma.

1 Disponível em <http://sawareru.jp/en/>

Anais [Pôster] do $7^{\circ}$ Congresso Internacional de Design da Informação | CIDI 2015

Proceedings [Poster] of the 7th Information Design International Conference / IDIC 2015 
A utilização de metodologias de design que valorizem o usuário parece ser o ponto chave para garantir projetos cada vez mais acessíveis. Entretanto, as tecnologias assistivas ainda são recursos paliativos para um mundo que, ainda, não é acessível a todos. As TA são recursos extremamente importantes para garantir a autonomia e independência àqueles que possuem alguma deficiência ou limitação, seja ela temporária ou permanente.

$\mathrm{Na}$ busca por ampliar as possibilidades de ferramentas de inclusão, o artigo traz, como exemplo, a impressora 3D. Ela é uma tecnologia que está sendo utilizada em diferentes áreas, conseguindo levar a prototipagem rápida que antes era apenas encontrada nas grandes indústrias para as pequenas e médias empresas e como está se tornando financeiramente mais acessível, a cada dia, já é possível encontrá-la até dentro de algumas residências.

Os estudos de casos apresentados exploram o uso da impressão 3D na criação de objetos de aprendizagem táteis responsáveis pela inclusão do acesso a informação por usuários com deficiência visual. Ao reproduzir elementos bidimensionais extraídos de microscópios e telescópios para imagens em três dimensões, possibilitou o princípio de design universal da informação perceptível levando a informação, através de diferentes meios de apresentação, aos alunos, incluindo àqueles com limitações sensoriais. Além de proporcionar o uso equitativo ao criar um design útil, atraente e seguro e sem estigamatizar ou segregar qualquer um de seus usuários.

Portanto, a impressão 3D aparece como uma promissora ferramenta que, segundo os estudos de casos apresentados, pode contribuir em projetos de design da informação. Ao explorar os diferentes sentidos, além da visão, aliados aos conceitos do design universal, demonstra o quanto é reducionista colocar o design da informação como pertencente a uma área específica do design (gráfico) por acreditar em uma amplitude maior. Os objetos de aprendizagem táteis permitem aumentar o número de usuários fornecendo a mesma informação, através de diferentes canais sensoriais, de modo que ela possa ser utilizada com eficiência e eficácia, buscando atender não só aqueles que têm necessidades especiais, mas garantindo o acesso livre e ilimitado a todos. O desafio é grande pois é sempre importante lembrar que todo usuário é único e a espécie humana bastante diversificada a ponto de ser enquadrada em condutas ou regras.

\section{Referências}

AAGAARD, P.; KOLITSKY, M. A. 3-D Printing, Copyright, and Fair Use: What Should We Know? Charleston Library Conference. Purdue University, Indiana, 2013. $<$ http://docs.lib.purdue.edu/cgi/viewcontent.cgi?article=1512\&context=charleston >, 25/07/2014.

ADAM, D. L.; MACEDO, C. M. S. A imagem como veículo de acesso à informação em objetos de aprendizagem para deficientes visuais. Desenhando na Escuridão. InfoDesign, São Paulo. v. 10. n. 2. p. $176-192,2013$.

$\mathrm{BERSCH}, \mathrm{R}$. Introdução à tecnologia assistiva. Assistiva: tecnologia e educação. Porto Alegre, 2013. <http://www.assistiva.com.br/Introducao_Tecnologia_Assistiva.pdf >, 25/07/2014.

GRUENWALD, L. Impressão 3d: lendo imagens através do tato. Um recurso a mais para estudantes com deficiência visual. Revista nacional de reabilitação - reação. n. 98. Maio/ Junho, 2014. < http://www.revistareacao.com.br/website/pdfs/cadernos/98.pdf>, 25/07/2014.

HAYWARD, V.; ASTLEY, O. R.; CRUZ-HERNANDES, M.; GRANT, D.; ROBLES-DE-LA-TORRE, G. Haptic interfaces and devices. Sensor Review. v. 24, n. 1, p. 16-29, 2004. <http://www.emeraldinsight.com/journals.htm?articleid=1509219>, 21/05/2014.

HORN, R. E. Information design: emergence of a new profession. In: JACOBSON, Robert (org.). Information Design, p.16-17. Cambridge: MIT Press, 1999.

HORTON, S. Access by Design: A guide to Universal Usability for Web Designers. 1. ed. 
Berkeley: New Riders, Pearson Education, USA. v. 1. 265 p. 2006.

IIID. International Institute for Information Design. 2007. <www.iiid.net/PDFs/idxPublication.pdf >, 25/05/2014.

IMS. Instructional Management Systems: Guidelines for Developing Accessible Learning Applications. 2002. <http://www.imsglobal.org/accessibility/accessiblevers/sec11.html>, 08/05/2014.

RADABAUGH, M. P. Study on the Financing of Assistive Technology Devices of Services for Individuals with Disabilities - A report to the president and the congress of the United State, National Council on Disability. 1993. <http://www.ncd.gov/publications/1993/Mar41993>, 24/07/2014.

SBDI. Sociedade Brasileira do Design da Informação. 2001. <www.sbdi.org.br>, 28/05/2014.

SHEDROFF, N. Information interaction design: A unified field theory of design. In: JACOBSON, Robert (org.). Information Design, p.267-292. Cambridge: MIT Press, 1999.

TOSCANO, Gabriel. Ciência para cego sentir. Ciência Hoje On-line. Publicado em 25 de maio de 2014. <http://cienciahoje.uol.com.br/blogues/bussola/2014/05/ciencia-para-cego-sentir>, 23/07/2014.

WILDBUR, P.; BURKE, M. Information graphics: Innovative solution in contemporary design. London: Thames and Hudson, 1998.

\section{Sobre os autores}

Natal Chicca Junior, MSc, UFPE, Brazil <natal@virtual.ufc.br >

Leonardo Gómez Castillo, PhD, UFPE, Brazil <leonardo.a.gomez@gmail.com>

Solange Galvão Coutinho, PhD, UFPE, Brazil <solange.coutinho@ufpe.br> 